\title{
PENANGANAN KLASIFIKASI KELAS DATA TIDAK SEIMBANG DENGAN RANDOM OVERSAMPLING PADA NAIVE BAYES (Studi Kasus: Status Peserta KB IUD di Kabupaten Kendal)
}

\author{
Reza Dwi Fitriani ${ }^{1 *}$, Hasbi Yasin ${ }^{2}$, Tarno ${ }^{3}$ \\ 1,2,3 Departemen Statistika, Fakultas Sains dan Matematika, Universitas Diponegoro \\ *e-mail rezadwifitriani05@gmail.com
}

\begin{abstract}
The Family Planning Program (KB) launched by the Government of Indonesia to address the problem of population control does not always produce the desired program results. In 2017, there were 7 users of the IUD contraceptive type of contraceptive who failed from 1,102 new IUD users in Kendal Regency so that the ratio of success and failure to the IUD KB program when compared to users of the new IUD KB is $0.64 \%: 99.36 \%$. The ratio of success and failure of family planning programs which tend to be unbalanced makes it difficult to predict. One of the handling imbalanced data is oversampling, for example using Random Oversampling (ROS). Naive Bayes is used for classification because it's easy and efficient learning model. The data in this study used 14 independent variables and 1 dependent variable. The results of this study indicate that the G-mean of Naive Bayes is less than $60 \%$. The G-mean of ROS-Naive Bayes is $96.6 \%$. It can be concluded that in this research, the ROS-Naive Bayes method is better than the Naive Bayes method for detecting the success status of IUD family planning in Kendal Regency.
\end{abstract}

Keywords: Naive Bayes, Random Oversampling, G-mean

\section{PENDAHULUAN}

Klasifikasi merupakan sebuah proses untuk menemukan sebuah model yang menjelaskan dan membedakan konsep atau kelas data dengan tujuan memperkirakan kelas dari suatu objek yang kelasnya tidak diketahui (Tan et al., 2006). Naive Bayes merupakan metode klasifikasi yang sering digunakan karena proses algoritmanya yang lebih cepat dan mudah serta robust terhadap data pencilan (Prasetyo, 2012). Klasifikasi dapat diterapkan dalam berbagai aspek sehingga seiring berjalannya waktu metode klasifikasi cukup banyak dikembangkan, namun terdapat permasalahan yang sering ditemui dalam klasifikasi yaitu masalah ketidakseimbangan data.

Ketidakseimbangan data terjadi ketika salah satu kelas memiliki jumlah yang jauh lebih besar dibanding kelas lainnya sehingga menyebabkan menurunnya kinerja klasifikasi pada kelas minoritas. Kinerja algoritma machine learning biasanya dievaluasi dengan akurasi hasil prediksi, namun hal ini tidak sesuai apabila terjadi ketidakseimbangan kelas (Chawla et al., 2002). Metode machine learning cenderung memberi label berupa kelas mayoritas pada data yang diprediksi dan mengabaikan kelas minoritas sehingga hanya akan menghasilkan akurasi hasil prediksi yang baik bagi kelas mayoritas saja .

Salah satu kasus klasifikasi dengan rasio tidak seimbang adalah status keberhasilan pasien program Keluarga Berencana jenis alat kontrasepsi Intra Uterine Device (IUD). Kegagalan pemakaian alat kontrasepsi IUD setiap tahunnya cenderung di bawah 5\% dari angka keberhasilannya, sebagai contoh pada tahun 2017 di Kabupaten Kendal tercatat sejumlah 7 pengguna KB jenis alat kontrasepsi Intra Uterine Device (IUD) mengala mi 
kegagalan dari 1.102 pengguna KB IUD baru secara sehingga jika dibandingkan antara jumlah berhasil dan tidak berhasil program KB IUD dengan berdasarkan pengguna KB IUD baru adalah sebesar 0,64 persen dibanding 99,36 persen (BKKBN, 2017). Adanya data tidak seimbang untuk proses klasifikasi menyebabkan hasil klasifikasi data minor menjadi tidak tepat atau tertutupi oleh prediksi data mayor sehingga dibutuhkan solusi untuk mengatasi masalah tersebut salah satunya yaitu melakukan oversampling misalnya dengan Random Oversampling (ROS) agar rasio ketimpangan kelas bisa dikurangi.

Penelitian klasifikasi dengan kelas tidak seimbang telah banyak dilakukan, salah satunya oleh Mutrofin et al. (2019) yang mengusulkan penerapan algoritma $k$-Nearest Neighbor pada kasus pemilihan calon siswa baru memberikan hasil untuk data yang tidak seimbang nilai $\mathrm{k}$ yang optimal yaitu $\mathrm{k} \geq 100$. Ustyannie \& Suprapto (2020) menerapkan metode Random Oversampling pada Regresi Logistik untuk data Thennar diperoleh akurasi terbaik dibanding kedua metode sampling lainnya yaitu sebesar 78,26\%.

Penerapan algoritma yang mengabaikan kelas data yang tidak seimbang akan menghasilkan prediksi yang baik pada kelas mayor, sedangkan kelas minor diabaikan (Chen et al., 2018). Algoritma klasifikasi akan mengalami penurunan performa jika menghadapi kelas data yang tidak seimbang (García et al., 2012). Penelitian ini menggunakan metode Random Oversampling (ROS) yang dikombinasikan pada Naive Bayes untuk memprediksi keberhasilan pasien program KB jenis alat kontrasepsi IUD Kabupaten Kendal dengan kondisi kelas data tidak seimbang.

\section{TINJAUAN PUSTAKA}

\subsection{Imbalanced Class Data}

Imbalanced data merupakan kondisi data yang tidak berimbang antara kelas data satu dengan kelas data yang lain. Kondisi imbalanced data menjadi masalah dalam klasifikasi karena classifier learning akan condong memprediksi ke kelas data yang banyak (mayoritas) dibanding dengan kelas yang sedikit (minoritas). Akibatnya, dihasilkan akurasi prediksi yang baik terhadap kelas data training yang banyak (kelas mayoritas) sedangkan untuk kelas data training yang sedikit (kelas minoritas) akan dihasilkan akurasi prediksi yang buruk (Chawla, 2003).

\subsection{Feature Selection}

Langkah paling sederhana dalam feature selection adalah dengan mengamati setiap feature yang dibangkitkan secara independen dan menguji kemampuan diskriminasinya pada masalah yang harus diselesaikan (Prasetyo, 2014). Langkah ini membantu membuang feature dengan kemampuan diskriminasi yang buruk dan mempertahankan feature dengan kemampuan diskriminasi yang baik sehingga mampu mengurangi kompleksitas model dan waktu komputasi. Feature selection dapat dilakukan antara lain dengan menggunakan uji independensi Chi-Square dan uji independensi Mann-Whitney.

\subsection{Naive Bayes}

Algoritma Naive Bayes berakar pada teorema Bayes. Teorema Bayes merupakan teorema yang mengacu pada konsep probabilitas bersyarat (Tan et al., 2006). Metode ini merupakan pendekatan statistik untuk melakukan inferensi induksi pada persoalan klasifikasi. Misalkan $A$ dan $B$ adalah kejadian dalam ruang sampel. Teorema Bayes secara matematis, teorema ini dapat diekspresikan sebagai berikut:

$$
P(A \mid B)=\frac{P(A \cap B)}{P(B)}
$$

Menurut Prasetyo (2014), jika $\boldsymbol{X}$ merupakan vektor yang berisi fitur dan $Y$ adalah label kelompok, Naive Bayes dituliskan dengan $P(Y \mid X)$. Nilai tersebut berarti probabilitas label 
kelompok $Y$ didapatkan setelah fitur-fitur $\boldsymbol{X}$ diamati. Notasi ini disebut juga probabilitas akhir untuk $Y$, sedangkan $P(Y)$ disebut probabilitas awal untuk $Y$. Formula Naive Bayes untuk klasifikasi adalah sebagai berikut:

Dengan $Y=Y_{i}, i=1,2,3 \ldots, k$

$$
P(Y \mid \boldsymbol{X})=\frac{P(Y) \prod_{g=1}^{p} P\left(X_{g} \mid Y\right)}{P(X)}
$$

$P(Y \mid \boldsymbol{X})$ adalah probabilitas data dengan vektor $\boldsymbol{X}$ pada kelompok $Y$

$P(Y)$ adalah probabilitas awal kelompok $Y$

$\prod_{g=1}^{p} P\left(\boldsymbol{X}_{\boldsymbol{g}} \mid Y\right)$ adalah probabilitas independen $Y$ dari semua feature dalam vektor $\boldsymbol{X}$ $P(\boldsymbol{X})$ adalah probabilitas dari $\boldsymbol{X}$.

Probabilitas $P(\boldsymbol{X})$ selalu tetap sehingga dalam perhitungan prediksi dapat dihilangkan dan hanya menghitung bagian $P(Y) \prod_{g=1}^{p} P\left(\boldsymbol{X}_{\boldsymbol{g}} \mid Y\right)$ dengan memilih nilai yang terbesar sebagai kelompok yang terpilih sebagai hasil prediksi. Sementara probabilitas independen $\prod_{g=1}^{p} P\left(\boldsymbol{X}_{\boldsymbol{g}} \mid Y\right)$ merupakan pengaruh semua feature dari data terhadap setiap kelompok $Y$, yang dinotasikan dengan:

$$
P(\boldsymbol{X} \mid Y=y)=\prod_{g=1}^{p} P\left(\boldsymbol{X}_{\boldsymbol{g}} \mid Y=y\right) \operatorname{dan} \boldsymbol{X}=\left[X_{1}, X_{2}, X_{3}, \ldots, X_{p}\right]
$$

Umumnya, Bayes mudah dihitung untuk feature bertipe kategorik, namun untuk feature dengan tipe numerik (non kategorik) ada perlakuan khusus sebelum diproses menggunakan Naive Bayes (Prasetyo, 2012). Caranya adalah:

a. Melakukan diskritisasi pada setiap feature kontinu dan mengganti nilai feature kontinu tersebut dengan nilai interval diskrit. Pendekatan ini dilakukan dengan mentransformasi feature ke dalam feature ordinal.

b. Mengasumsikan bentuk tertentu dari distribusi probabilitas untuk feature kontinu dan memperkirakan parameter distribusi dengan data training. Distribusi Gaussian biasanya dipilih untuk mempresentasikan probabilitas bersyarat dari feature kontinu pada sebuah kelompok $P\left(X_{g} \mid Y\right)$, sedangkan distribusi Gaussian dikarakteristikkan dengan dua parameter yaitu mean $(\mu)$ dan varian $\left(\sigma^{2}\right)$ untuk setiap kelompok $Y_{i}$, probabilitas bersyarat kelompok $Y_{i}$ untuk feature $X_{g}$ adalah $P\left(X=x_{g} \mid Y=y_{1}\right)=g\left(x_{g}, \mu_{g i}, \sigma_{g i}\right)$, dengan

$$
g\left(x_{g}, \mu_{g i}, \sigma_{g i}\right)=\frac{1}{\sqrt{2 \pi} \sigma_{g t}} e^{\left(\frac{x_{g i}-\mu_{g i}}{2 \sigma_{g t}}\right)^{2}}, i=1,2 \text { dan } g=1,2,3, \ldots, p
$$

Parameter $\mu_{g i}$ diperoleh dari sampel $X_{g}(\bar{X})$ dari semua data training yang memiliki kelompok $Y_{i}$, sedangkan $\sigma_{g i}^{2}$ dapat diperkirakan dari varian sampel $\left(s^{2}\right)$ dari data training.

Menurut Hastuti (2016) model klasifikasi yang tidak memerlukan asumsi non multikolinieritas dan normalitas antara lain Metode Naive Bayes dan Decision Tree. Nä̈ve Bayes mengaplikasikan Teorema Bayes yang mengestimasi parameter mengikuti distribusi data sedangkan Decision Tree bersifat nonparametrik. Oleh karena itu, kedua metode tersebut dapat digunakan untuk mengklasifikasikan data yang tidak memenuhi asumsi normal.

\subsection{Random Oversampling (ROS)}

Random Oversampling (ROS) merupakan penambahan data dari kelas minoritas ke dalam data training secara acak. Proses penambahan ini diulang sampai jumlah data kelas minoritas sama dengan jumlah kelas mayoritas. Pertama dihitung selisih antara kelas mayoritas dengan kelas minoritas. Selanjutnya, dilakukan perulangan sebanyak hasil 
penghitungan selisih sambil membaca data kelas minoritas secara acak dan ditambahkan ke dalam data training (Chawla et al., 2002). Berikut adalah flowchart algoritma Random Oversampling (Saifudin \& Wahono, 2015):

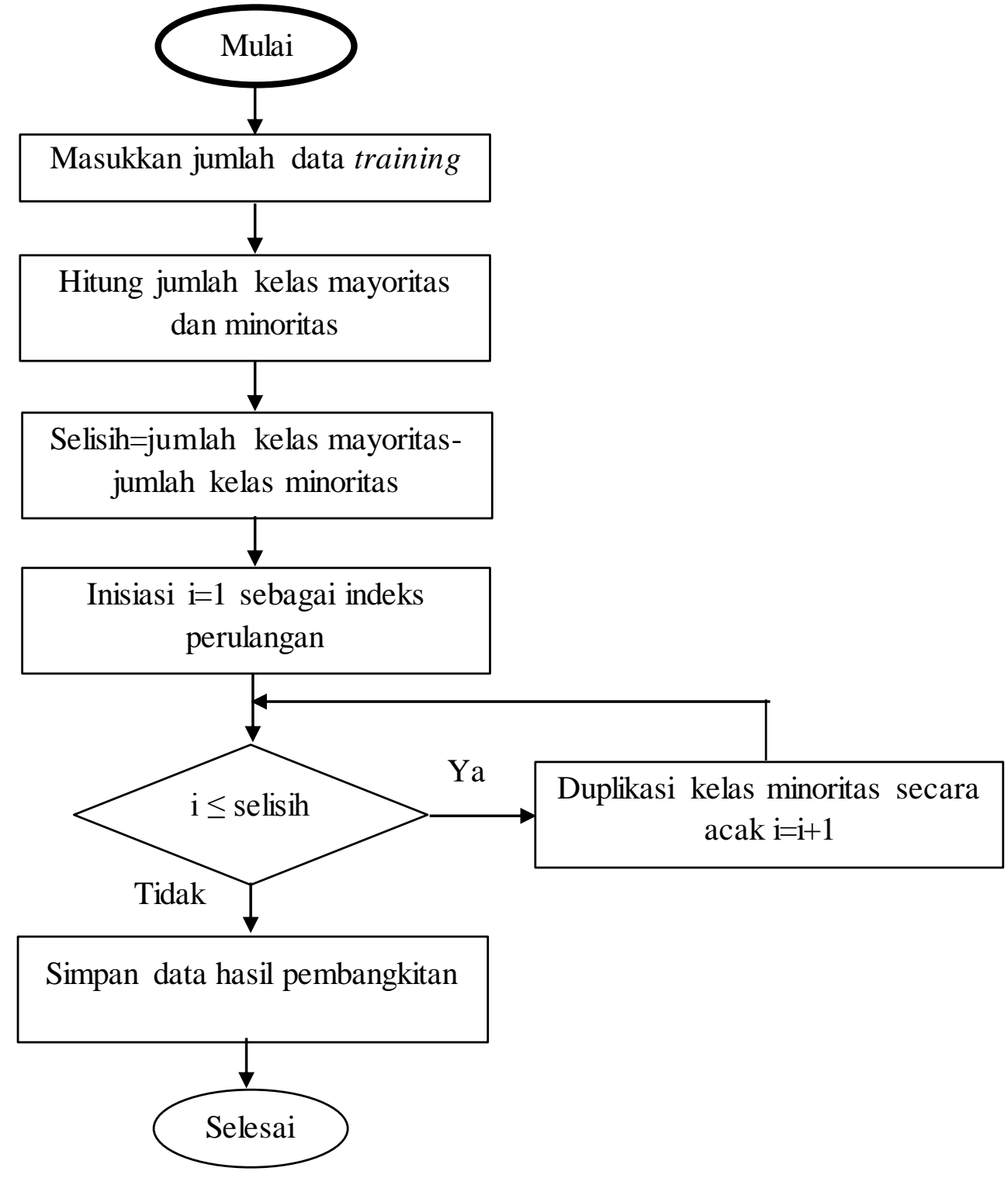

Gambar 1. Flow Chart Algoritma Random Oversampling 


\subsection{Ukuran Kinerja Klasifikasi}

Kasus kelas tidak seimbang dengan kelas mayoritas 98-99\% dari keseluruhan populasi akan menghasilkan hasil klasifikasi akan mencapai akurasi tinggi karena hanya melihat kelas mayoritas saja. Jelas bahwa untuk kasus kelas tak seimbang, akurasi klasifikasi tidak cukup sebagai ukuran kriteria standar (Pangastuti et al., 2018). Evaluasi kinerja metode secara keseluruhan dapat dilakukan dengan menggunakan geometric mean ( $G$-mean). G-mean merupakan rata-rata geometrik sensitivitas dan spesifisitas (Kubat \& Matwin, 1997)

$$
\begin{gathered}
\text { Akurasi }=\frac{\mathrm{TP}+\mathrm{TN}}{(\mathrm{TP}+\mathrm{FP}+\mathrm{FN}+\mathrm{TN})} \times 100 \% \\
\text { Spesifisitas }=\frac{T N}{(T N+F P)} \times 100 \% \\
\text { Sensitivitas }=\frac{T P}{(T P+F N)} \times 100 \% \\
G-\text { Mean }=\sqrt{\text { Sensitivitas } \times \text { Spesifisitas }}
\end{gathered}
$$

\subsection{Holdout Cross Validation}

Salah satu cara untuk membagi data training dan data testing yang paling sederhana adalah holdout cross validation. Holdout cross validation akan membagi data menjadi 2 bagian dengan proporsi tertentu yang ditentukan oleh peneliti. Proporsi yang biasa digunakan oleh peneliti adalah 60/40, 70/30, atau 80/20 (Raschka, 2018). Proporsi data pelatihan lebih besar dibandingkan dengan data uji. Proporsi yang dipilih harus tepat yaitu tidak terlalu besar untuk data pelatihan karena akan menyebabkan validasi dengan data uji menjadi kurang mencerminkan keakuratan model sebenarnya.

\section{METODE PENELITIAN}

\subsection{Data Penelitian}

Data yang digunakan dalam penelitian ini adalah data status peserta Keluarga Berencana (KB) jenis alat kontrasepsi Intra Uterine Device (IUD) Kabupaten Kendal pada tahun 2018. Data tersebut merupakan data sekunder yang diperoleh dari formulir kartu status peserta KB K/IV Petugas Lapangan Keluarga Bencana (PLKB) Badan Kependudukan dan Keluarga Berencana Nasional (BKKBN) Kabupaten Kendal tahun 2018 dan dilakukan proses pengambilan data pada Januari 2019. Data diambil dari responden yang telah memasang KB jenis IUD sejak 2015, diperoleh sebanyak 250 pasien dan terdapat 15 variabel.

\subsection{Variabel Penelitian}

Variabel yang digunakan dalam penelitian ini terdiri dari variabel dependen (Y) dan beberapa variabel independen $(\mathrm{X})$ dengan rincian sebagai berikut:

1. Variabel dependen $\mathrm{Y}=$ Status keberhasilan KB IUD, $1=$ berhasil, $0=$ tidak berhasil

2. Variabel independen

$\mathrm{X}_{1}=$ Usia, $\mathrm{X}_{2}=$ Cara KB terakhir, $\mathrm{X}_{3}=$ Status menyusui, $\mathrm{X}_{4}=$ Pendarahan pervaginam, $\mathrm{X}_{5}=$ Keputihan, $\mathrm{X}_{6}=$ Riwayat tumor, $\mathrm{X}_{7}=$ Berat badan, $\mathrm{X}_{8}=$ Tekanan darah sistolik, $\mathrm{X}_{9}=$ Tekanan darah diastolik, $\mathrm{X}_{10}=$ Posisi rahim, $\mathrm{X}_{11}=$ Radang, $\mathrm{X}_{12}=$ Tumor ganas ginekologi, $\mathrm{X}_{13}=$ Diabetes, dan $\mathrm{X}_{14}=$ Kelainan pembekuan darah . 


\subsection{Analisis Data}

Software yang digunakan untuk pengolahan data ini adalah RStudio versi 1.1.463. Metode yang digunakan adalah Synthetic Minority Oversampling Technique (SMOTE), Random Oversampling (ROS), dan Naive Bayes. Langkah-langkah analisis data pada penelitian ini adalah sebagai berikut:

1. Input data

2. Melakukan analisis deskriptif

3. Melakukan pre-processing

4. Melakukan pembagian data training dan data testing

5. Melakukan copy data training menjadi tiga data training

6. Melakukan klasifikasi dengan Naive Bayes

7. Melakukan pengukuran kebaikan klasifikasi Naive Bayes

8. Melakukan klasifikasi dengan ROS-Naive Bayes

9. Melakukan pengukuran kebaikan klasifikasi ROS-Naive Bayes

10. Menentukan model klasifikasi terbaik diantara Naive Bayes dan ROS-Naive Bayes berdasarkan ukuran kebaikan klasifikasi.

\section{HASIL DAN PEMBAHASAN}

\subsection{Rasio Variabel Dependen}

Berdasarkan data status keberhasilan KB IUD 250 pasien di BKKBN Kabupaten Kendal tahun 2018 terlihat bahwa terdapat 235 pasien (94\%) status program pasien KB berhasil dan 15 pasien lainnya tidak berhasil dalam menjalani program KB jenis IUD. Distribusi frekuensi status keberhasilan KB IUD dapat dilihat pada Gambar 3.

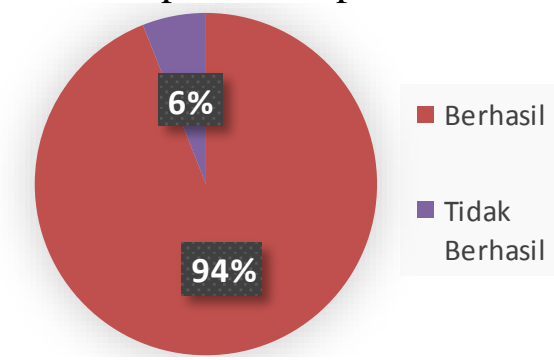

Gambar 2. Persentase Status Keberhasilan KB IUD

\subsection{Feature Selection}

a) Uji Independensi Chi-Square

Hipotesis yang digunakan pada uji ini yaitu:

$\mathrm{H}_{0}$ : Tidak terdapat hubungan antara variabel independen dengan variabel dependen

$\mathrm{H}_{1}$ : Terdapat hubungan antara variabel independen dengan variabel dependen

Taraf Signifikansi $\alpha=0,05$

Statistik Uji

$$
\begin{gathered}
\chi^{2}=\sum_{i=1}^{n} \sum_{j=1}^{m}\left[\frac{\left(o_{i j}-E_{i j}\right)^{2}}{E_{i j}}\right] \\
E_{i j}=\frac{\left(n_{i .}\right)\left(n_{. j}\right)}{N}
\end{gathered}
$$

$\mathrm{O}_{\mathrm{ij}}$ : Frekuensi obyek teramati baris ke-i dan kolom ke-j $\left(n_{i j}\right)$.

$\mathrm{E}_{\mathrm{ij}}$ : Frekuensi harapan obyek baris ke-i dan kolom ke-j.

derajat kebebasan $\mathrm{dk}=(\mathrm{r}-1)(\mathrm{c}-1)$

$\mathrm{r}$ : banyaknya baris

c : banyaknya kolom

Kaidah Pengambilan Keputusan 
$\mathrm{H}_{0}$ ditolak apabila nilai $\chi^{2}>\chi_{\alpha,(r-1)(c-1)}^{2}$ atau nilai signifikansi $<\alpha$.

Hasil perhitungan nilai Chi-Square dan probabilitas masing-masing variabel ditampilkan pada Tabel 1.

Tabel 1. Hasil Uji Chi-Square

\begin{tabular}{ccc}
\hline Variabel & Chi-Square & Signifikansi \\
\hline $\mathrm{X}_{2}$ & 23,847 & 0,000 \\
$\mathrm{X}_{3}$ & 93,705 & 0,000 \\
$\mathrm{X}_{4}$ & 1,6285 & 0,202 \\
$\mathrm{X}_{5}$ & 18,861 & 0,000 \\
$\mathrm{X}_{6}$ & 3,931 & 0,047 \\
$\mathrm{X}_{10}$ & 39,623 & 0,000 \\
$\mathrm{X}_{11}$ & 18,573 & 0,000 \\
$\mathrm{X}_{12}$ & 43,608 & 0,000 \\
$\mathrm{X}_{13}$ & 22,182 & 0,000 \\
$\mathrm{X}_{14}$ & 3,653 & 0,056 \\
\hline
\end{tabular}

Berdasarkan Tabel 2 dapat disimpulkan bahwa variabel $\mathrm{X}_{2}, \mathrm{X}_{3}, \mathrm{X}_{5}, \mathrm{X}_{6}, \mathrm{X}_{10}, \mathrm{X}_{11}, \mathrm{X}_{12}, \mathrm{X}_{13}$, dan $\mathrm{X}_{14}$ yang berhubungan dengan variabel dependen $(\mathrm{Y})$.

b) Uji Independensi Mann-Whitney

Hipotesis yang digunakan pada uji ini yaitu:

$$
\begin{aligned}
& \mathrm{H}_{0}: \mathrm{M}_{\mathrm{x}}=\mathrm{M}_{\mathrm{y}} \\
& \mathrm{H}_{1}: \mathrm{M}_{\mathrm{x}} \neq \mathrm{M}_{\mathrm{y}}
\end{aligned}
$$

Taraf Signifikansi $\alpha=0,05$

Statistik Uji

$$
T=S-\frac{n_{1}\left(n_{1}+1\right)}{2}
$$

Pengujian dengan data berukuran besar $\left(\mathrm{n}_{1}, \mathrm{n}_{2}>20\right)$ dapat didekati dengan distribusi normal sebagai berikut:

$\mathrm{t}$ : jumlah ties

$$
Z=\frac{T-\frac{\left(n_{1} n_{2}\right)}{2}}{\sqrt{\frac{n_{1} n_{2}\left(n_{1}+n_{2}+1\right)}{12}-\frac{n_{1} n_{2}\left(\sum t^{3}-\sum t\right)}{12\left(n_{1}+n_{2}\right)\left(n_{1}+n_{2}-1\right)}}}
$$

$\mathrm{n}_{1}$ : jumlah data populasi 1

$\mathrm{n}_{2}$ : jumlah data populasi 2

Probabilitas hasil uji Mann-Whitney masing-masing variabel ditampilkan pada Tabel 2.

\begin{tabular}{cc} 
Tabel 2. Hasil Uji Mann-Whitney \\
\hline Variabel & Signifikansi \\
\hline $\mathrm{X}_{1}$ & 0,003 \\
$\mathrm{X}_{7}$ & 0,002 \\
$\mathrm{X}_{8}$ & 0,085 \\
$\mathrm{X}_{9}$ & 0,000
\end{tabular}

Berdasarkan Tabel 3 dapat disimpulkan bahwa variabel $\mathrm{X}_{1}, \mathrm{X}_{7}$, dan $\mathrm{X}_{9}$ yang berhubungan dengan variabel dependen (Y).

Pada analisis selanjutnya akan dibandingkan pula klasifikasi antara data non feature selection dan data dengan feature selection menggunakan model Naive Bayes dan ROSNaive Bayes pada tiga bentuk split data yaitu 75/25, 80/20, dan 85/15. 


\subsection{Hasil Klasifikasi dengan Naive Bayes dan ROS-Naive Bayes}

Model pembelajaran klasifikasi yang dibangun pada penelitian ini adalah Naive Bayes sedangkan metode oversampling yang digunakan yaitu ROS. Prediksi dilakukan pada data training dan data testing yang telah dibagi dengan metode holdout cross validation. Proporsi split data training dan data testing yang digunakan pada penelitian ini ada tiga macam yaitu $75 / 25$, 80/20, dan 85/15 dengan membandingkan antara tanpa feature selection dan menggunakan feature selection pada data. Hasil klasifikasi data test dapat ditampilkan pada Tabel 3.

Tabel 3. Hasil Klasifikasi Data Testing

\begin{tabular}{|c|c|c|c|c|c|}
\hline Feature Selection & Model & Akurasi & Sensitivitas & Spesifisitas & G-mean \\
\hline \multicolumn{6}{|c|}{ Proporsi Split Data Testing 75/25 } \\
\hline \multirow{2}{*}{ Tidak } & Naive Bayes & 0,952 & 0,250 & 1,000 & 0,500 \\
\hline & ROS-Naive Bayes & 0,921 & 1,000 & 0,915 & 0,957 \\
\hline \multirow{2}{*}{ Ya } & Naive Bayes & 0,952 & 0,250 & 1,000 & 0,500 \\
\hline & ROS-Naive Bayes & 0,937 & 1,000 & 0,932 & 0,966 \\
\hline \multicolumn{6}{|c|}{ Proporsi Split Data Testing 80/20 } \\
\hline \multirow{2}{*}{ Tidak } & Naive Bayes & 0,960 & 0,333 & 1,000 & 0,577 \\
\hline & ROS-Naive Bayes & 0,960 & 1,000 & 0,957 & 0,978 \\
\hline \multirow{2}{*}{ Ya } & Naive Bayes & 0,960 & 0,333 & 1,000 & 0,577 \\
\hline & ROS-Naive Bayes & 1,000 & 1,000 & 1,000 & 1,000 \\
\hline \multicolumn{6}{|c|}{ Proporsi Split Data Testing $85 / 15$} \\
\hline \multirow{2}{*}{ Tidak } & Naive Bayes & 0,973 & 0,500 & 1,000 & 0,707 \\
\hline & ROS-Naive Bayes & 0,973 & 1,000 & 0,971 & 0,986 \\
\hline \multirow{2}{*}{ Ya } & Naive Bayes & 0,973 & 0,500 & 1,000 & 0,707 \\
\hline & ROS-Naive Bayes & 0,838 & 1,000 & 0,829 & 0,910 \\
\hline
\end{tabular}

\subsection{Perbandingan Hasil Klasifikasi}

Hasil klasifikasi yang sudah diperoleh kemudian dibandingkan ukuran kebaikan klasifikasi berdasarkan model, penggunaan feature selection, dan split data.

\section{a) Perbandingan Model}

Rata-rata ukuran hasil klasifikasi data testing model Naive Bayes dan ROS-Naive Bayes. dapat ditampilkan pada Tabel 4.

Tabel 4. Perbandingan Model

\begin{tabular}{ccc}
\hline $\begin{array}{c}\text { Ukuran } \\
\text { Kebaikan Model }\end{array}$ & Naive Bayes & $\begin{array}{c}\text { ROS- } \\
\text { Naive Bayes }\end{array}$ \\
\hline Akurasi & 0,962 & 0,938 \\
Sensitivitas & 0,361 & 1,000 \\
Spesifisitas & 1,000 & 0,934 \\
G-mean & 0,595 & 0,966 \\
\hline
\end{tabular}

Berdasarkan Tabel 4 nilai akurasi kedua model berada di atas 93\%. Setelah dilakukan pembangkitan data dengan ROS akurasinya lebih kecil dibandingkan sebelum dilakukan balancing data, namun nilai $G$-meannya jauh lebih besar yaitu 0,966. Model sebelum dan sesudah dilakukan ROS mempunyai nilai sensitivitas yang sangat berbeda, apabila tidak 
dilakukan ROS maka model Naive Bayes memiliki sensitivitas yang sangat kecil. Nilai sensitivitas yang kecil pada Naive Bayes mengindikasikan bahwa model tersebut tidak mampu melakukan klasifikasi secara benar untuk pasien tidak berhasil KB IUD. Model yang baik adalah model yang mampu melakukan klasifikasi secara tepat pada semua jenis kelas. Algoritma ROS memperbaiki hasil klasifikasi menjadi jauh lebih baik terlihat bahwa nilai G-mean lebih besar dibandingkan tanpa balancing sehingga model ROS-Naive Bayes dinilai yang terbaik untuk model klasifikasi data KB IUD Kabupaten Kendal.

\section{b) Perbandingan Penggunaan Seleksi Fitur}

Rata-rata ukuran hasil klasifikasi data testing penggunaan feature selection pada data dapat ditampilkan pada Tabel 5.

\begin{tabular}{ccc} 
Tabel 5. Perbandingan Penggunaan & Feature Selection \\
\hline Ukuran & Non & Feature \\
Kebaikan Model & Feature Selection & Selection \\
\hline Akurasi & 0,957 & 0,943 \\
Sensitivitas & 0,681 & 0,681 \\
Spesifisitas & 0,974 & 0,960 \\
G-mean & 0,784 & 0,777 \\
\hline
\end{tabular}

Berdasarkan Tabel 5 hasil klasifikasi data non feature selection menghasilkan nilai $G$ mean yang lebih tinggi dibandingkan hasil klasifikasi data yang dilakukan feature selection. Hal ini dapat dikatakan model klasifikasi data non feature selection dinilai lebih baik dibandingkan klasifikasi data yang dilakukan feature selection.

\section{KESIMPULAN}

1. Terdapat 11 variabel independen yang memiliki asosiasi terhadap variabel respon, yaitu variabel usia $\left(\mathrm{X}_{1}\right)$, variabel cara $\mathrm{KB}$ terakhir $\left(\mathrm{X}_{2}\right)$, variabel status menyusui $\left(\mathrm{X}_{3}\right)$, variabel keputihan $\left(\mathrm{X}_{5}\right)$, variabel riwayat tumor $\left(\mathrm{X}_{6}\right)$, variabel berat badan $\left(\mathrm{X}_{7}\right)$, variabel darah diastolik $\left(\mathrm{X}_{9}\right)$, variabel posisi rahim $\left(\mathrm{X}_{10}\right)$, variabel radang $\left(\mathrm{X}_{11}\right)$, variabel tumor ganas ginekologi $\left(\mathrm{X}_{12}\right)$, dan variabel diabetes $\left(\mathrm{X}_{13}\right)$.

2. Berdasarkan hasil klasifikasi yang dilakukan dengan dua cara yaitu dengan feature selection dan non feature selection, terlihat bahwa rata-rata ukuran kebaikan klasifikasi model nonfeature selection lebih baik dibanding dengan feature selection karena rata-rata $G$-mean model non feature selection lebih besar dibandingkan dengan feature selection.

3. Hasil klasifikasi terbaik untuk diterapkan pada klasifikasi status keberhasilan program KB tahun 2018 adalah metode ROS-Naive Bayes. Hal ini dikarenakan nilai sensitivitas dan $G$-mean data testing yang lebih tinggi dibandingkan Naive Bayes sehingga apabila peneliti ingin prediksi secara lebih akurat untuk kelas tidak berhasil KB IUD Kabupaten Kendal maka lebih baik menggunakan metode ROS-Naive Bayes.

\section{DAFTAR PUSTAKA}

BKKBN. (2017). Laporan Program KB Nasional, Dalap Tabel 8 A Kumulatif. Tersedia di: http:/aplikasi.bkkbn.go.id/sr/Klinik/Laporan2013/Bulanan/Faskes2013Tabe18aKum ulatif.aspx (Diakses pada: 26 February 2021). 
Chawla, N. V (2003). C4.5 and Imbalanced Data Sets : Investigating the Effect of Sampling Method, Probabilistic Estimate, and Decision Tree Structure. ICML Workshop Learning from Imbalanced Data Sets II. Washington D.C.

Chawla, N. V., Bowyer, K. W., Hall, L. O. \& Kegelmeyer, W. P. (2002). SMOTE: Synthetic Minority Over-sampling Technique. Journal of Artificial Intelligence Research Vol. 16, No. 2, Hal: 321-357.

Chen, L., Fang, B., Shang, Z., \& Tang, Y. (2018). Tackling class overlap and imbalance problems in software defect prediction. Software Quality Journal Vol. 26, No. 1, Hal: 97-125 doi: 10.1007/s11219-016-9342-6.

García, V., Sánchez, J. S. \& Mollineda, R. A. (2012). On the effectiveness of preprocessing methods when dealing with different levels of class imbalance. Knowledge-Based Systems, Vol: 25, No. 1, Hal: 13-21. doi: 10.1016/j.knosys.2011.06.013.

Hastuti, Y. (2016). Klasifikasi Karakteristik Mahasiswa Universitas Cokroaminoto Palopo Menggunakan Metode Naive Bayes dan Decision Tree. Jurnal Dinamika Vol. 07, No. 2, Hal: 34-41.

Kubat, M. \& Matwin, S. (1997). Addressing the Curse of Imbalanced Training Sets: OneSided Selection. Fourteenth International Conference on Machine Learning Hal: 179186.

Mutrofin, S., Mualif, A., Ginardi, R. V., \& Fatichah, C. (2019). Solution of Class Imbalance of K-Nearest Neighbor for Data of New Student Admission Selection. International Journal of Artificial Intelligence Research Vol. 3, No. 2, Hal: 47-55. doi: 10.29099/ijair.v3i2.92.

Pangastuti, S. S., Fithriasari, K. \& Irawan, N. (2018). Perbandingan Metode Ensemble Random Forest dengan Smote-Boosting dan Smote-Bagging pada Klasifikasi Data Mining untuk Kelas Imbalance. Surabaya: Institut Teknologi Sepuluh Nopember.

Prasetyo, E. (2012). Data Mining - Konsep dan Aplikasi Menggunakan MATLAB. Yogyakarta: ANDI.

Prasetyo, E. (2014). Data Mining - Mengolah Data Menjadi Informasi Menggunakan Matlab. Yogyakarta: ANDI.

Raschka, S. (2018). Model evaluation, model selection, and algorithm selection in machine learning .

Saifudin, A. \& Wahono, R. P. (2015). Pendekatan Level Data untuk Menangani Ketidakseimbangan Kelas pada Prediksi Cacat Software. Journal of Software Engineering Vol. 3, No. 2, Hal: 47-55.

Tan, P., Steinbach, M., \& Kumar, V. (2006). Introduction to Data Mining. Boston: Pearson Education

Ustyannie, W., \& Suprapto, S. (2020). Oversampling Method to Handling Imbalanced Dataset Problem in Binary Logistic Regression Algorithm. Indonesian Journal of Computing and Cybernetics Systems Vol. 14, No.1, Hal: 1-10. doi: 10.22146/ijccs.37415. 